\title{
The Multimodal Representational Characteristics of Mandarin Children's Disagreement — A Case Study Based on Diachronic Videos
}

\author{
Rongbin Wang, Rui Zhang \\ School of Foreign Languages, Shanxi University, Taiyuan, China \\ Email address: \\ 283841728@qq.com (Rongbin Wang),15103418154@163.com (Rui Zhang)
}

\section{To cite this article:}

Rongbin Wang, Rui Zhang. The Multimodal Representational Characteristics of Mandarin Children's Disagreement — A Case Study Based on Diachronic Videos. International Journal of Language and Linguistics. Vol. 8, No. 3, 2020, pp. 115-121.

doi: $10.11648 /$ j.ijll.20200803.14

Received: May 8, 2020; Accepted: June 4, 2020; Published: June 15, 2020

\begin{abstract}
Based on a case study, this research collects naturally happened videos of one mandarin-speaking child during the period of her 1.5-3.5 years old, and makes a thorough study of the multimodal representational characteristics of disagreement of this child from the perspective of Multimodal Discourse Analysis. Within a data corpus constituted by 80 hours' videorecorded life traces of a pre-school child, a corpus of 114 cases of disagreement was selected for a qualitative analysis through the Elan software. It is shown that mandarin-speaking children of this age period usually conduct multimodal communicative behaviors when they are expressing disagreement, the modal forms of which include verbal disagreement, nonverbal disagreement, verbal-nonverbal disagreement. To be more specific, verbal-nonverbal disagreement involves two kinds of modal interactional relationships: equivalent and complementary with the latter containing reinforced and non-reinforced cases. Through this research, parents and early educational staffs are suggested to pay more attention on children's multimodal expressions on the one hand and to employ more non-verbal resources in interacting with young children on the other hand. What's more, the point of individual differences of children is a time-consuming but simultaneously a noteworthy one for both parents and preschool teachers. The results of this study bring further light on the knowledge of early education and parental involvement.
\end{abstract}

Keywords: Mandarin-speaking Children, Disagreement, Multimodal Discourse Analysis, Diachronic Videos Study

\section{Introduction}

The word "disagreement" was defined as "a situation in which people express different opinions about something and sometimes argue" in the LONGMAN Dictionary of Contemporary English. Linguistic scholars have started to study disagreement since the 1980s, when most studies of disagreement are carried out from the perspective of Speech Act. From the point of view of Conversation Analysis, Pomerantz found that when making response to opinion, disagreement was a typical type of dispreferred organization in contrast to agreement [1]. By studying on agreement and disagreement in a predominantly female computer-mediated group, Baym summarized that features of this form of communication were different from that of the spoken or written mode, in the way that disagreement in this context was more mitigated [2]. From the perspective of Intercultural Communication, Yang conducted a research on Chinese and American college students to find the different patterns of disagreement of these two groups. The result revealed that indirect expressions of disagreement were more commonly used in the group of Chinese college students, while direct expressions of disagreement were more commonly used in the other group [3]. In the early stage of studies on politeness principles, disagreement was mainly regarded as an impolite and face-threatening behaviour. However, Sififianou's finding represented that disagreement brought not only conflicts and impoliteness, but also affinities and socialization, in which way the relationship between interlocutors would be enhanced [4]. Angouri drawed on data from two projects on workplace discourse situated in Europe and the analysis of the data showed that 'deviating opinions' 
were not only 'acceptable' but also unmarked. Being different form marked disagreement, unmarked disagreement was perceived as task bound and did not pose a threat to the management of the meeting participants' complex identities and relationships [5].

Later, it was further realized that treating disagreement as a pure linguistic phenomenon was not quite appropriate. Seen also as a social act, disagreement was defined as "an oppositional stance (verbal or non-verbal) to an antecedent verbal (or non-verbal) action" by Kakavá [6]. Bressem and Müller focused on a set of gestures employed by Germans in expressing negative comments, which included sweeping away, holding away, throwing away and brushing away [7]. Bressem et al. studied two repeated gestures in German: sweeping away and holding away, showing that these two gestures together with other situated factors constituted the whole context meaning [8]. Mehu et al. examined the influence of low-level visual and auditory cues on the communication of agreement and disagreement. As was found, statements of disagreement were able to be distinguished from that of agreement and neutral utterances based on nonverbal cues alone [9]. In Khaki et al.'s study, JESTKOD database was employed to investigate roles of vocal and gesture cues on identifying a dyadic interaction as agreement or disagreement [10]. From the perspective of Semiotics, disagreement behaviour could be realized not only through verbal resources, but also non-verbal resources, such as eye gaze, facial expression, gesture and body movement, etc. Different semiotic resources could work together to have disagreement behavior realized [11]. Within a data corpus constituted by 30 video-recorded meals of 10 Swiss and Italian families, Antonio Bova and Francesco Arcidiacono found that both parents and children assume argument schemes related to the object of the disagreement [12]. Amanda S. Haber et al. compared 120 first graders tested during the 2014-2015 academic year, who received a direct instruction-based curriculum, with 112 first graders tested in the same school system during the 2016-2017 academic year, who received an inquiry-based curriculum and they concluded that the graders who received an inquiry-based curriculum were more likely to resolve disagreements concerning facts correctly [13]. Alexa Kane and Barbara A. Morrongiello studied the impact of children's temperament on how parents resolve safety disagreements during preadolescence and found that youth may be more inclined to support the parent's safety rules if they feel supported and that their position has been heard by the parent [14].

As was shown above, researches on children's disagreement are still insufficient by far, especially from the aspect of children's multimodal disagreement. Considering this, this paper collects and analyzes naturally happened videos of a mandarin-speaking child (during the period of her 1.5-3.5 years old), attempting to find the multimodal representational characteristics of her acts of disagreement and to summarize possible development of her multimodal disagreement at different stages. The results are thought to be inspiring for the early education of preschool children.

\section{Corpus Collection and Annotation}

Employing the method of case analysis, this paper takes a close look at mandarin-speaking children's disagreement with videos of naturally happened life traces as its corpus. At the beginning point of recording, the target-child, female, was 1.5 years old and was still in the development of linguistic competence, and could already understand simple instructions of parents and made responses accordingly. At the finishing point of recording, the target-child was 3.5 years old and was relatively maturer in the development of linguistic competence. Specifically speaking, videos were taken among the time interval of 1;06;03 (age; month; day)$3 ; 06 ; 03$, the process of which lasted for about two years. Finally, researcher collected videos of 80 hours in total, which were finally abstracted into 2 hours and 28 minutes' children disagreement video clips. These clips were further numbered into 114 cases of disagreement and were annotated in the software of ELAN for Multimodal Discourse Analysis.

\section{Results and Discussion}

Halliday recognized verbal products as a kind of social acts and recognizes the realization of a social act as a process of meaning making [15]. From the perspective of Multimodal Systemic Functional Linguistics, this research regards children's disagreement behavior as a result through a process of choice-making from a multimodal system, seeing verbal disagreement as one kind of multimodal sources in disagreement. Analysis of the target videos shows that there are three kinds of disagreement: verbal disagreement, nonverbal disagreement, verbal-nonverbal disagreement, which make up 22\%, 27\%, 51\% respectively (see Table 1).

Table 1. Disagreement and semiotic modals used.

\begin{tabular}{ll}
\hline Disagreement & Frequency \\
\hline Verbal disagreement & 25 \\
Nonverbal disagreement & 31 \\
Verbal-nonverbal disagreement & 58 \\
Total & 114 \\
\hline
\end{tabular}

As is revealed in Table 1, the target child, during her 1.53.5 age period, tends to use verbal-nonverbal disagreement most frequently, nonverbal disagreement less frequently, and single verbal disagreement the least frequently. Considering that children of this age are in the period of rapid cognitive and linguistic development, the whole developmental period is further divided into four sections, that is, 1.5-2.0, 2.0-2.5, 2.5-3.0 and 3.0-3.5 years old.

\subsection{The Multimodal Representation of Mandarin Children's Disagreement: 1.5-2.0-year-old Period}

For this period, 32 target materials are found in total, among which verbal disagreement, nonverbal disagreement, verbal-nonverbal disagreement are 3, 17, 12 cases respectively (see Table 2 ). The figures show that the child during this period uses nonverbal disagreement more often, which is understandable. At this age, it is more likely a hard 
task for children to speak on their own verbal resources and limited language competence force them into employing nonverbal expressions, as in Example 1 and in Example 2.

Table 2. Realization of Disagreement by Children aged 1.5-2.0.

\begin{tabular}{ll}
\hline Disagreement & Frequency \\
\hline Verbal disagreement & 3 \\
Nonverbal disagreement & 17 \\
Verbal-nonverbal disagreement & 12 \\
Total & 32 \\
\hline
\end{tabular}

In Example 1, the child picked up a plastic piece from the table and put it into her mouth, the movement of which triggered her mother's prevention, that is, grabbing the plastic piece by hand. In response, the child turned her head and showed an oppositional stance. In this example, the child delivers a gesture of turning her head to express disagreement.

Example 1

PAR: You cannot eat this. It is plastic.

Bù néng chī, băo bèi zhè ge shì sù liào.

(Gesture: Grabbing the plastic piece by hand.)

CHI: \# (Gesture: Turning her head to avoid mom's hand.) \#

(Content between \# is disagreement, the same below)

[1; 10; 12-13 (year; month; day-video number, the same below)]

In Example 2, the family was having dinner while the child's aunt was using a spoon for feeding the child. However, the child took the spoon back and ate by herself, the behavior of which in this context reflects her disagreement. In this example, the child's disagreement is realized by a non-verbal gesture: taking the spoon back.

Example 2

PAR2: Give me the spoon so that I can feed you.

Geǐ lăo yí ge sháo zi, weì băo bèi xī fàn.

(Gesture: Feeding.)

CHI: \# (Gesture: Taking the spoon back. ) \#

[1; 10;1-9]

Verbal-nonverbal disagreement happens when children employ verbal sources and nonverbal sources at the same time to express disagreement. Zhang classified the relationships of modal interactions into two kinds: complementary and non-complementary [16]. In detail, the complementary relationship included reinforced one, in which one modal was the dominant part and the rest of modals were the assistant parts, and non-reinforced one, in which all modals were equally important. On the contrary, the non-complementary relationship meant that each modal can represent the whole meaning alone. Capirci et al. studied behaviours of Italian-speaking children aged from one year and four months to one year and eight months and found that verbal and nonverbal sources presented three kinds of relationships: equivalent, complementary and supplementary [17]. Specifically, in this paper video clips of disagreement present equivalent and complementary relationships, with the latter showing reinforced and non-reinforced cases. In Example 3, the child and parents were playing out of doors when the child was having a distance from her mother. The mother asked her child to "come over". However, the child asked her mother to "come over" in turn and waved hands at the same time. In this example, verbal languages and two gestures are used simultaneously to express disagreement, representing an equivalent modal relationship.

Example 3

PAR: Come over.

Guò lái.

CHI: \# Come over. \#

\# Guò lái. \#

PAR: Come over.

Guò lái.

CHI: \# Come over. \#

\# Guò lái. \#

\# (Gesture: Crooking fingers repeatedly.) \#

\# (Gesture: Waving hands.) \#

$[1 ; 09 ; 14-24]$

In Example 4, the child wanted to share her food with mother so that she walked to her mother and raised one of her hands toward her mom's mouth. After the mother expressed a negative attitude, she insisted her stance and could not help stooping her feet, with her mouth mumbling. In this example, the dominant modal is made up of her gesture and body movement, and the assistant part is linguistic mumbling, which constitute one of complementary reinforced cases. In this example, verbal languages and nonverbal sources are used simultaneously to realize disagreement.

Example 4

CHI: \# (Body movement: Walking toward her mother.) \#

\# (Gesture: Raising spoon toward her mother.) \#

PAR: Mom do not eat, baby.

Băo bèi chī ba, māmā bù chī.

CHI: \# Humph! Humph! \#

\# (Body movement: Walking toward her mother.) \#

\# (Gesture: Raising spoon toward her mother.) \#

\# (Body movement: Stooping feet.) \#

$[1 ; 08 ; 05-21]$

In Example 5, the child walked down stairs and then reached out her hands toward her mother for help. After the mother displayed a different opinion, the child made a strong disagreement: mumbling loudly with her hands reaching to mom strongly. Video materials show that the child under observation often mumbles in displaying disagreement. However, neither mumbling nor reaching hands alone can express the whole meaning, that is, asking for mother's help. In this way, the verbal resource and body movement present a complementary non-reinforced relationship.

Example 5

PAR: You can do this, baby.

CHI: \# Humph. Humph. \#

\# (Body movement: Reaching hands to mother.) \#

$[1 ; 08 ; 26-22]$

During the observation period when the child is at the age of 1.5-2.0, we have not observed many examples of disagreement in which only verbal resource is applied. The main reason is possibly that children of this age period are not able to express themselves freely by words. Instead, they 
tend to employ nonverbal resources to make supplements to limited verbal signs. In Example 6, for instance, the child soiled her pants and then her father was changing pants for her. During the process, the father delivers his reason of wearing pants, "It is cold". The child, however, disagrees with her father's opinion with verbal products.

Example 6

PAR: Put on your trousers, it's cold.

Chuān shàng kù kù, liáng le.

CHI: \# Not cold, not cold. \#

Bù liáng, bù liáng.

$[1 ; 11 ; 05-32]$

\subsection{The Multimodal Representation of Mandarin Children's Disagreement: 2.0-to-2.5-year-old Period}

During this period, 20 target materials in total are found, among which the number of verbal disagreement, nonverbal disagreement, verbal-nonverbal disagreement are 7, 3, 10 cases respectively (see Table 3 ). The figures show that, being different from the feature of the child aged 1.5-2.0, at this age the target-child did not use nonverbal disagreement as frequently, but used verbal-nonverbal disagreement more frequently. In this period, the child under observation has acquired a relatively higher linguistic competence: she could use complete verbal expressions instead of single word or phrase. In the meanwhile, the child is able to control her emotion in a better way so that she uses less body movements to fulfill disagreement (see Example 8).

Table 3. Realization of Disagreement by Children aged 2.0-2.5.

\begin{tabular}{ll}
\hline Disagreement & Frequency \\
\hline Verbal disagreement & 7 \\
Nonverbal disagreement & 3 \\
Verbal-nonverbal disagreement & 10 \\
Total & 20 \\
\hline
\end{tabular}

Example 7 shows the example of verbal-nonverbal disagreement. Under this circumstance, parents intended to go out and the child displayed an oppositional stance in response. At the beginning, the child was on her way upstairs and after the situation was introduced she turned around to approach her mother. The child used the rhetorical device of repetition to emphasize her verbal meaning, which is also the dominant resource in representing this disagreement. In this way, the multimodal relationship of Example 7 belongs to the type of complementary reinforcement. In this example, the linguistic mode, that is, "Mom cannot go to work! Mom cannot go to work!", eye gaze, facial expression and body movement work together to express disagreement.

Example 7

GRA: Parents are going to work! TT stay with grandma and grandpa.

Ràng bà bà mā mā shàng bān! TT gēn yé ye năi nai dāi zhe.

CHI: \# Mom cannot go to work! Mom cannot go to work! \#

Mā mā bù shàng bān!Mā mā bù shàng bān!
\# (Facial expression: Browning.) \#

\# (Gaze: Glaring.) \#

\# (Body movement: Going downstairs.) \#

$[2 ; 00 ; 17-36]$

Example 8 is a single verbal disagreement, in which the child utilized a syntactically complete sentence. The circumstance is that parents were going out and grandma suggested to hold the child in arms, which confronted the disagreement of the child.

Example 8

GRA: Let Granma hold you, baby.

Năi năi bào yí xià băo bèi.

CHI: Granma \# does not \# hold baby.

Năi năi bú bào băo bèi.

$[2 ; 00 ; 17-36]$

In Example 9, the child was choked in the middle of dinner and the mother put her hand under the child's mouth. In response, the child turned around her head, displaying a disagreement act. This case is one of those few cases of nonverbal disagreement at this stage.

Example 9

CHI: \# (Body movement: Dogging.) \#

$[2 ; 05 ; 12-34]$

\subsection{The Multimodal Representation of Chinese Children's Disagreement: 2.5-to-3.0-year old Period}

During this period, we find 47 target materials in total, among which there are 13, 8, 26 cases of verbal disagreement, nonverbal disagreement, verbal-nonverbal disagreement respectively (see Table 4). The figures show that the most frequently happened representation is still the verbal-nonverbal disagreement.

Table 4. Realization of Disagreement by Children aged 2.5-3.0.

\begin{tabular}{ll}
\hline Disagreement & Frequency \\
\hline Verbal disagreement & 13 \\
Nonverbal disagreement & 8 \\
Verbal-nonverbal disagreement & 26 \\
Total & 47 \\
\hline
\end{tabular}

In Example 10, the father argued with the child that the child would be afraid of aliens. The child expressed her disagreement on this point, and laughed in the meanwhile. In this example, verbal source is the dominant model in displaying whole meaning and smiling is the assistant part, thus belonging to the relationship of complementary reinforcement. In this example, the smile weakened the degree of disagreement of the child, showing her lacking of self-confidence in disagreeing with father's opinion. At this stage, the combination of oppositional verbal speech and smile happen 13 times in total, displaying a higher cognitive competence. In this way she has learned to deploy different resources and to regulate the degree of disagreement.

Example 10

PAR: You're afraid of aliens, hah?

Nǐ pà wài xīng rén ne?

CHI: \# No. \#

Bú pà. 
\# (Facial expression: Smiling.) \#

$[2 ; 11 ; 11-72]$

In Example 11, the child was FaceTiming with her aunt on one hand and using fitness facility on the other hand. The mother suggested her to hang up the phone, which was faced with the disagreement of the child. In this situation, the child uses complete verbal expression to present her disagreement clearly and her parents show respect for her decision.

Example 11

PAR: Hang up.

Guà le ba.

CHI: \#No.\#

Bú guà.

[2; 07; 14-86]

In this period, the frequency of nonverbal disagreement ranks the last one. Being different from nonverbal expressions at the stage of 1.5-2.0, the child in this period uses more tender body movements, such as smiling, silence and moving away. It can be implied from videos that children of this age probably tend to use indirect disagreement more often other than direct disagreement such as stooping, body resisting, etc. This change shows that children of this age period must have learned more efficient expressions as they grow. In Example 12, the child was playing in the muddy puddle, while her mother reminded her of keeping hands clean. However, the child used a body movement, that is, touching puddle with hands, to express her disagreement.

Example 12

PAR: You will spoil your hands.

Shǒu huì nòng zāng de.

CHI: \# (Body movement: Playing puddle with hands.) \#

$[2 ; 11 ; 15-55]$

\subsection{The Multimodal Representation of Chinese Children's Disagreement: 3.0-to-3.5-year old Period}

During this period, 15 cases of disagreement in total are found, among which the number of verbal disagreement, nonverbal disagreement, verbal-nonverbal disagreement are 2, 3, 10 cases respectively (see Table 5). The figures show that the most frequently used representation of disagreement is still the verbal-nonverbal disagreement.

Table 5. Realization of Disagreement by Children aged 3.0-3.5.

\begin{tabular}{ll}
\hline Disagreement & Frequency \\
\hline Verbal disagreement & 2 \\
Nonverbal disagreement & 3 \\
Verbal-nonverbal disagreement & 10 \\
Total & 15 \\
\hline
\end{tabular}

In Example 13, the child was playing with her friend in the stone hole area and her friend took the lead in getting out of the hole. The child under research used verbal and nonverbal modes together to display disagreement, among which the verbal mode is the dominant modal in expressing disagreeing meaning and the other modes including facial expressions and body movement are assistant ones.

Example 13
CHI: \# Let me get out first, hum! \#

Wǒ xiān shàng lái, hèng!

\# (Body movement: Reaching hands toward the mother.) \#

\# (Facial expression: Browning.) \#

\# (Facial expression: Pouting.) \#

$[3 ; 04 ; 28-98]$

In Example 14, the child was having dinner. In case of a stomach, the mother suggested her child not to eat too much but the child employed nonverbal modes, that is, keep dining, to show her oppositional stance.

Example 14

PAR: You are full, huh?

Chī băo le ba?

CHI: \# (Body movement: Eating.) \#

PAR: You are not going to eat, huh?

Bù chī le ba?

CHI: \# (Body movement: Eating.) \#

[3;03; 3-87]

In Example 15, the mother wanted to taste the child's chocolate bar and therefore asked for it for three times. In response, the child made use of verbal-nonverbal disagreement twice and verbal disagreement once.

Example 15

PAR: I have eaten just now? I want to eat more.

Wǒ gāng gāng jiù chī la?wǒ haí xiăng chī le.

CHI: Em, \#no\#.

En, bù xíng.

$[3 ; 13 ; 23-101]$

\section{Conclusion}

This research is a case study based on diachronic videos, in which a mandarin-speaking child's daily life traces are recorded and the way of her expressing disagreement is analyzed in detail. According to the statistical analysis above, it is implied that mandarin-speaking children aged 1.5-3.5 also tend to use three kinds of semiotic representations in expressing disagreement, the form of which includes verbal disagreement, nonverbal disagreement and verbal-nonverbal disagreement. In total, the collaborated way, namely multimodal disagreement, is presented in videos most frequently. It is well-known that language is the most efficient way in communication. However, at the early age of child development, specially at the stage of 1.5-2.0, Mandarin-speaking children usually resort to nonverbal resources to express disagreement, for their limited linguistic competence. Consequently, lots of nonverbal disagreement at the first stage are found. When children grow older, at the stage of 2.0-2.5, they acquire a higher linguistic competence and can use simple but semantically completed sentences. In this way, the proportion of verbal-nonverbal disagreement raises to the top. At the same time, children's self-care ability is unable to keep pace with their linguistic competence, which conducts their strong body conflicts with parents. Take Example 7, the child uses nonverbal resource to enhance the degree of disagreement. Although verbal-nonverbal disagreement still accounts for the highest proportion at the 
age of 2.5-3.0, this kind of disagreement shows different features from that of the previous stage. Children begin to employ more tender expressions in all aspects of semiotic types to express disagreement, the phenomenon of which is reflected in the video clips, taking the combination of verbal opposition and smiling as an example. At the period of 3.03.5 , with children's more involvement in social activities, the diversity of expressions of disagreement becomes richer in both verbal and nonverbal representation. When playing with other children, the targeted child could recognize boundaries between her stuffs and others' and could use specific semiotic resources to display her disagreement.

After learning about the multimodal representational characteristics of mandarin-speaking children's disagreement, it can be inferred that at the early age (1.5-2.0), children are in lack of the capability of complete speech presentation. However, even though nonverbal resources are not efficient as verbal resources, their intuitive nature makes them easy to be applied. Through nonverbal products, parents and children can reach a situation of mutual understanding, and consequently avoid possible reverse psychology of children. Moreover, the multimodal representational characteristics of children present a certain degree of individual differences, which parents need to spend plenty of time on to gradually understand personalized non-verbal expressions of different children. Parents are suggested to use more conventional nonverbal expressions, to prepare their children for further multimodal social communication.

In addition, this research has some enlightenment on the field of early education in the following aspects:

First, at the early stage of children's development, especially when they have not acquired an integrated linguistic competence yet, early educational stuffs should pay close attention to children's nonverbal expressions and produce multimodal communication frequently. By using different kind of modals, such as body movement, facial expression and gaze, staffs probably win the chance to stimulate effective and multimodal interactions with children.

Second, when interacting with children at juvenile stage, one may encounter strong physical resistance. Considering that children of this stage are not capable enough in selfattending and therefore are more willing to express themselves, educators and parents are advised to place children in a safe environment where they can express themselves sufficiently, verbally or nonverbally. On the contrary, it is not suggested that stuffs deal with children's disagreement toughly, which may result in reverse psychology of children.

Third, professionals engaged in early education should pay attention to children's verbal expressions on the one hand and to children's multimodal acts on the other hand. This is because children's multimodal acts of disagreement are quite commonly. Especially, when verbal-nonverbal disagreement is employed and different modals present a complementary relationship, attenders' focusing only on a single modal cannot comprehend the whole text meaning. Besides, children's individual differences are also a noteworthy point to consider in parenting and schooling of children at early stage.

\section{Acknowledgements}

This research is a component of the 2018 research project "Video-corpus-based Study of Chinese-speaking Children's Multimodal Negating Act and Its Development" (18CYY022) sponsored by the National Social Science Foundation of China, the 2019 Shanxi Provincial Project of Philosophy and Social Science for Universities "A Video-corpus-driven Research on the Acquisition of Early-age Mandarin-speaking Children's Multimodal Negation" (2019W001) sponsored by the Shanxi Provincial Education Department and the 2020 Shanxi Provincial Project of Philosophy and Social Science for Universities "A developmental study of multimodal negating of Chinese autistic children" (2020W021) sponsored by the Shanxi Provincial Education Department.

\section{References}

[1] Pomerantz, Anita. (1984). Agreeing and disagreeing with assessments: some features of preferred/dispreferred turn shapes. In Atkinson, J. M., Heritage, J. (Eds.), Structures of Social Action. Studies in Conversation Analysis (pp. 75-101). Cambridge: Cambridge University Press.

[2] Baym, Nancy. (1996). Agreements and Disagreements in a Computer-Mediated Discussion. Research on Language and Social Interaction, 29, 315-346.

[3] Haoxin Yang. (2011). An Intercultural and Cross-Gender Study on Disagreement Realization Patterns of Chinese and American College Students. Unpublished Master's Thesis, Northwest Normal University, Gansu.

[4] Sififianou, Maria. (2012). Disagreements, Face and Politeness. Journal of Pragmatics, 44, 1554-1564.

[5] Angouri, Jo. (2012). Managing disagreement in problem solving meeting talk. Journal of Pragmatics, 44, 1565-1579.

[6] Kakavá, Christina. (1993). Negotiation of Disagreement by Greeks in Conversations and Classroom Discourse. Unpublished Doctoral Thesis, Georgetown University, Washington D. C.

[7] Bressem, J. \& Müller, C, (2014). Body Language Communication: An International Handbook on Multimodality in Human Interaction. Berlin: Degruyter Mouton Press.

[8] Bressem, J., Stein, N., \& Wegener, C. (2017). Multimodal Language Use in Savosavo. Pragmatics, 2, 173-206.

[9] Mehu, Marc.\& van der Maaten, Laurens. (2014). Multimodal Integration of Dynamic Audio-Visual Cues in the Communication of Agreement and Disagreement. Journal of nonverbal behaviour, 38 (4), 569-597.

[10] Khaki, Hossein. \& Bozkurt, Elif. \&Erzin, Engin. (2016). Agreement and Disagreement Classification of Dyadic Interactions Using Vocal and Gestural Cues. International Conference on Acoustics Speech and Signal Processing ICASSP, 2762-2766. 
[11] Rongbin Wang, Yaoqin Xue. (2020). On the Multimodal Representation of 4 5-year-old Chinese-speaking Children's Negative Behavior. Studies in Preschool Education, No. 1, 20-29.

[12] Antonio Bova, Francesco Arcidiacono. (2018). The interplay between parental argumentative strategies, children's reactions and topics of disagreement during family conversations. Learning, Culture and Social Interaction, 1-10.

[13] Amanda S. Haber, David M. Sobel \& Deena Skolnick Weisberg. (2019). Fostering Children's Reasoning about Disagreements through an Inquiry-base Curriculum. Journal of Cognition and Development, 1-19. https://doi.org/10.1080/15248372.2019.1639713.
[14] Alexa Kane, Barbara A. Morrongiello. (2020). The Impact of Children's Temperament on How Parents Resolve Safety Disagreements During Preadolescence. Journal of Pediatric Psychology, 45 (2), 218-228.

[15] Zhuanglin $\mathrm{Hu}$ et al. 2005. An Introduction to Functional Grammar. Beijing: Peking University Press.

[16] Delu Zhang. (2009). On A Synthetic Theoretical Framework for Multimodal Discourse Analysis. Foreign Language in China, 24-30.

[17] Capirci O, Iverson M J, et al. (1996). Gestures and words during the transition to two word speech. Journal of Child Language, 23, 645-673. 